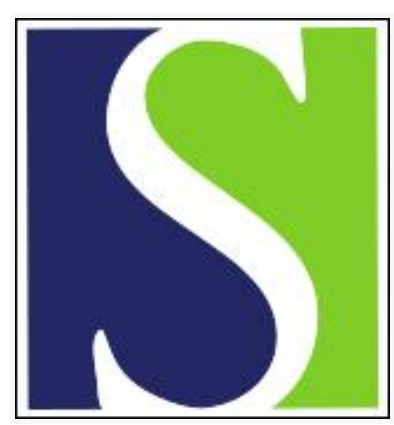

Scand J Work Environ Health 2001;27(4):217-218

https://doi.org/10.5271/sjweh.607

Issue date: Aug 2001

Acrylamide in tunnel construction - new (or old) lessons to be learned?

by Kjuus $\mathrm{H}$

Affiliation: National Institute of Occupational Health, Department of Occupational Medicine, PO Box 8149 Dep, N-0033 Oslo, Norway. Helge.Kjuus@stami.no

Refers to the following texts of the Journal: 2001;27(4):219-226 1999;25(4):335-341

The following article refers to this text: 2004;30(1):21-29

Key terms: acrylamide; editorial; tunnel construction

This article in PubMed: www.ncbi.nlm.nih.gov/pubmed/11560334 


\section{Acrylamide in tunnel construction — new (or old) lessons to be learned?}

Monomeric acrylamide is neurotoxic, probably carcinogenic to humans, and may have reproductive effects on animals $(1,2)$. Since the first report on acrylamide poisoning in man was published in 1953, more than 150 cases have been reported, mainly related to the primary production of acrylamide from acrylonitrile or to the polymerization of acrylamide to polyacrylamide. Polyacrylamide has not been shown to be toxic, but the polymer does contain small amounts of unreacted polymer.

Acrylamide grouts were introduced in the 1950s. When the acrylamide grout polymerizes, it solidifies into a stiff gel that is impervious to water and is suitable for waterproofing (eg, during tunnel construction). In the gel form, the grout contains less than $0.05 \%$ free acrylamide. The main exposure to the workers occurs during the mixing and pumping of the grouting solution and also during its injection. Only a few cases of acrylamide poisoning have been reported in relation to waterproofing, all during the 1960s and 1970s, when pure acrylamide grout dominated (3). The production of acrylamide grout ceased in the United States in the late 1970 s due to the producers' concern for its potential risk to humans.

Because of the toxic properties of acrylamide, another grout was developed, based on the less toxic Nmethylolacrylamide (NMA). In animal experiments, the neurotoxic potential of NMA has been reported to be $20-30 \%$ of the toxicity of acrylamide (2).

In this issue of the Scandinavian Journal of Work, Environment \& Health, Hagmar and his colleagues report reversible health effects on the peripheral nervous system among 210 workers who, during a period of 8 weeks, injected $1340 \mathrm{t}$ of an NMA-based grouting agent during tunnel construction in southern Sweden (4). For 23 subjects there was strong evidence indicating that peripheral nervous functions were impaired due to occupational exposure to NMA or acrylamide. Environmental effects due to contamination of the drinking water were also observed that led to the development of severe neurological symptoms among cows and the death of fish downstream.

At exactly the same time, a similar incident occurred among Norwegian tunnel workers who were building a railway tunnel to the new 0 slo airport. Altogether, $340 \mathrm{t}$ of the NMA grout was used in this tunnel during a 2year period. Fewer subjects were exposed, but the observed symptoms and signs were similar, as reported for the Swedish workers (5). We are currently studying the possible irreversible effects of such exposure, focusing on neurography and visual function, including electroretinography, color vision, and vision field.

How can it happen that a toxic compound that has been studied in depth for decades can still lead to occupational and environmental accidents during construction work in two countries that both have a strong tradition of protecting the health and safety of workers?

Although the circumstances may be somewhat different in the two events, some common questions can at least be asked. In both tunnel projects, the water leakage became unexpectedly high, due to the extremely unstable rock structures in the tunnel area. In the Norwegian project, several of the small lakes in the area were almost emptied for water during the construction work. These environmental problems, with the potential disturbance of the ground water level, came in addition to the possible health risk to the workers. One may ask if these unexpected problems could have been avoided if the projects had been better planned.

This question leads to another: Is time pressure a new risk factor for occupational hazards? Are large construction projects subject to such tight time limits that crucial stages in both the planning and implementation of the projects suffer, with direct implications for the workers? The traditional grouting technique with cement is time consuming. It is easy to use more of the "fast" grouting agents, such as those based on acrylamide, when pressed for time. When grouting agents are used in tunnel projects, the common practice has been to inject them into the rock before blasting, thus preventing water leakage. However, due to the unexpected water leakages and the pressure on the available schedule for completing the tunnel, the grouts, at least in Norway, were also injected into fissures that leaked water after blasting. Thus the normal polymerization of the gel was incomplete and was disturbed by the water leakage. As the injection work often lasted until the leakage was under control, long workhours could evolve. Some Norwegian workers reported continuous work of up to 24 hours in order to finish a job. Could the use of these large amounts of NMA grout have been avoided given a different schedule? 
As the predominant uptake of NMA from the grout is believed to occur through the dermal route, another challenge in this kind of injection work is to prevent skin contact with the grouting agent. The Norwegian workers all used gloves, and the majority used rain coats and trousers. Still, 80\% reported skin contact with the grouting agent, and all reported skin contact with contaminated tunnel water and were "completely wet" from tunnel water. Correspondingly, Hagmar and his colleagues report that none of the workers had used appropriate personal protection devices (4).

In addition, the workers may not have been properly informed. In Norway, the material safety data sheet was incomplete, initially giving no information that the grouting solution contained acrylamide. Later information revealed that solution 1 of the grout contained $4-5 \%$ acrylamide as an "impurity". Stricter routines for the use of personal protective devices were introduced when this fact was discovered.

However, the actual content of acrylamide in the NMA grout during such atypical work conditions is highly unclear. NMA is produced from acrylamide and formaldehyde in an aqueous solution, in which the reaction is balanced in favor of NMA. The reaction is slightly reversible, NMA being hydrolyzed back to acrylamide. The extent to which this reversible reaction occurs in practice is not known and is dependent on environmental conditions. It has been shown that the reversibility increases with high $\mathrm{pH}$ and low temperature. Measurements in the Norwegian tunnel indicated a 2:1 ratio of the concentration of NMA to acrylamide in the tunnel water, compared with more than 10:1 in the NMA grout. Thus exposure to the mixed, but not yet polymerized product may have led to higher concentrations of acrylamide than previously anticipated.

One effective preventive measure is substitution when toxic substances are being dealt with. In Norway, the use of NMA-based grout was immediately stopped, mainly for environmental reasons, and substituted with other grouting agents. One of the alternative agents used contained isocyanates, which are scarcely expected to lead to a safer work environment. In a small cohort of Norwegian injection workers using isocyanatecontaining grouting agents, 7 of 19 workers developed obstructive lung disease (6). Thus the choice between alternative substitutes is not as obvious as one might believe.

The rapid action of a department of occupational and environmental medicine in a regional hospital, with immediate examination of several hundreds of subjects during a few weeks, is impressive. Thus it is beyond comprehension that well-established units with high competence in occupational hygiene and toxicology in Sweden at present seem to be disintegrated or downsized at the expense of "soft" worklife issues.

A recent Norwegian study indicates that tunnel construction still represents great preventive challenges in the protection of workers from occupational ill-health, also independently of the use of acrylamide-containing grout (7). However, these Scandinavian incidents of acrylamide-related health effects is a reminder to all experts dealing with the safe use and regulation of toxic substances in the workplace. Thus several lessons could be learned from these two tunnel projects, and, not surprisingly, most of the lessons seem to be old and well known. One new lesson might be that time pressure may represent an increasingly important determinant for occupational hazards.

\section{References}

1. World Health Organization (WHO). Acrylamide. Geneva: WHO, 1985. Environmental health criteria, no 49.

2. International Agency for Research on Cancer (IARC). Some industrial chemicals, Lyon: IARC, 1994:435-53. IARC monographs on the evaluation for carcinogenic risk of chemicals to humans, vol 60.

3. Hills BW, Greife AL. Evaluation of occupational acrylamide exposures. Appl Ind Hyg 1986;3:148—52.

4. Hagmar L, Törnqvist M, Nordander C, Rosén I, Bruze M, Kautiainen A, et al. Health effects of occupational exposure to acrylamide using hemoglobin adducts as biomarkers of internal dose. Scand J Work Environ Health 2001;27:219—26.

5. Kjuus H, Heier M, Goffeng LO, Øvrebø S, Skaug V, Sjøholm H, et al. Possible nervous system effects related to acrylamide and Nmethylolacrylamide exposure in tunnel work. Presented at the 26th International Congress on Occupational Health, Singapore, 27th August - 1st September 2000.

6. Ulvestad B, Melbostad E, Fuglerud P. Asthma in tunnel workers exposed to synthetic resins. Scand J Work Environ Health 1999;25:335-41.

7. Ulvestad B, Bakke B, Melbostad E, Fuglerud P, Kongerud J, Lund MB. Increased risk of obstructive pulmonary disease in tunnel workers. Thorax 2000;55:277-82.

Helge Kjuus

National Institute of Occupational Health

Department of Occupational Medicine

PO Box 8149 Dep

N-0033 Oslo Norway

(E-mail: Helge.Kjuus@stami.no) 